\title{
Lessons Learned: 'Balance-training' as a New Method Supporting former Intensive Care Patients in Adaptation and Self-management
}

Margo van Mol ${ }^{{ }^{*}}$, Hanneke Oonk ${ }^{2}$ and Lilian Vloet ${ }^{3,4}$

${ }^{1}$ Erasmus MC University Medical Center, Department of Intensive Care Adults, Rotterdam, Netherlands

${ }^{2}$ Registertherapist $B C Z$ and $M B S R$ trainer, Huizen, Netherlands

${ }^{3}$ HAN University of Applied Sciences, Department of Emergency and critical care, Nijmegen, Netherlands

${ }^{4}$ Radboud University Medical Center, Scientific Center for Quality of Healthcare (IQ healthcare), Nijmegen, Netherlands

\section{Abstract}

Background: The long run physical, cognitive and emotional consequences of admission to an intensive care unit (ICU) are well-known. However, the ongoing debate on the best practices supporting the former ICU patients and their relatives for these consequences, is still inconclusive. A new method, 'Balance-training', has been developed to stimulate the regaining of emotional and physical capability.

Aim: The study aimed to explore the experiences of trainees on both the individual intake questionnaire and the group-based programme of Balance-training.

Methods: Eight ICU survivors in a central region of the Netherlands, voluntarily participated in the study. They started their Balance-training in January or March 2016, with the same coaches and outline of the course. The course included psycho-education, mindfulness-based stress reduction exercises, and peer support during a 10-week programme. The design of the pilot study was a longitudinal mixed method. Semi-structured interviews were audiotaped, transcribed, and fragmented until the point of saturation. Open, axial, and selective coding were used to analyze the results. A questionnaire was sent to the respondents before $(=\mathrm{t} 1)$, at the end $(=\mathrm{t} 2)$, and three months after finishing $(=\mathrm{t} 3)$ the Balancetraining.

Results: All respondents stated that they appreciated the Balance-training and would recommend it to others. The combination of group-based psycho-education, peer support, and mindfulness-based stress reduction exercises seemed to suffice the ICU survivors, increasing self-management and personal wellbeing. A positive effect on depression, anxiety and stress level was measured, however, the differences in $\mathrm{t} 1, \mathrm{t} 2$, and $\mathrm{t} 3$ were not further analyzed due to a limited number of respondents. The training offered the possibility to learn and grow from their own and others' experiences. The three pillars in the Balancetraining could provide a complete package in striving for personal growth and adaptation in ICU survivors.

Conclusion: Balance-training as a new method in the aftercare of ICU patients showed preliminary positive results in self-management and offered support and tools to take care of one's own emotional and physical balance in life.

\section{Introduction}

Admission into an intensive care unit (ICU) is associated with shortand long-term consequences for patients and their relatives [1-3]. In a recent study it was suggested that fewer than $10 \%$ of patients who received mechanical ventilation for more than four days are alive and fully independent one year later [4]. A large population-based cohort study found that $23 \%$ of ICU survivors were admitted to emergency departments within 30 days of discharge, thus emphasizing that postICU care should be improved [5]. Neuro-cognitive functioning of 800 respondents after critical illness showed similar results compared to patients with Alzheimers' disease, accordingly indicating moderate to severe cognitive deterioration [6]. In addition to the individual challenges of rehabilitation from the underlying disease, physical recovery, and cognitive regaining, the emotional distress needs to be addressed as well. Recently, the Post Intensive Care Syndrome (PICS) has been defined to emphasize the total impact of an ICU admission; "the new or worsening impairments in health status arising and the persistence of critical illness after hospitalization" $[2,7]$.

PICS is a clustering of symptoms in former ICU patients and describes physical impairment (e.g., pain, tiredness, muscles loss, sleep disturbances, swallowing problems), cognitive deterioration

\section{Publication History:}

Received: August 21, 2017

Accepted: November 25, 2017

Published: November 27, 2017

\section{Keywords:}

Balance-training, ICU patient, Intensive Care Unit, Mindfulnessbased stress reduction, Peer support, PICS, Psycho-education

\section{Abbreviations:}

ICU $=$ Intensive care unit MBSR $=$ mindfulness-based stress reduction

PICS $=$ Post intensive care syndrome (e.g., lack of concentration, memory problems, loss of multitasking), and emotional consequences (e.g., anxiety, depression, posttraumatic stress syndrome). Patients' relatives canalso suffer from PICS, although this is restricted to emotional consequences over the long term [4]. The insufficient ability to adapt to and self-manage emotional turmoil mayweaken and influence health [8]. Therefore, it is of utmost importance to provide understanding and supportto reduce the impact of an ICU admission.

The awareness of this impact has increased in ICU professionals. Hospitals have introduced new methods of aftercare such as rehabilitation treatment, post ICU clinics, and peer support $[2,9,10]$.

"Corresponding Author: Dr. Margo van Mol, Erasmus MC University Medical Center, Department of Intensive Care, P.O. Box 2040, 3000 CA, Rotterdam, Netherlands, Tel: +31 6 15566554; E-mail: m.vanmol@erasmusmc.nl

Citation: van Mol M, Oonk H, Vloet L (2017) Lessons Learned: 'Balance-training' as a New Method Supporting former Intensive Care Patients in Adaptation and Self-management. Int J Psychol Behav Anal 2: 134. doi: https://doi. org/10.15344/2017/2455-3867/134

Copyright: (c) 2017 van Mol et al. This is an open-access article distributed under the terms of the Creative Commons Attribution License, which permits unrestricted use, distribution, and reproduction in any medium, provided the original author and source are credited. 
However, the ongoing debate on best practices for supporting the former ICU patients and their relatives for the consequences of an ICU admission is still inconclusive. These best practices are therefore not generally implemented [11]. Another challenge is the successive support after these hospital-based interventions. GPs and other healthcare providers, such as counselors and psychologists, hardly recognize the symptoms of PICS. Moreover, patients themselves do not always associate their health status with their former ICU admission and consequently they maylack necessary treatment [12]. A new method, "Balance-training", has been developed to overcome these gaps and to stimulate the regaining of emotional and psychosocial capability in ICU survivors. The study aimed to explore the experiences of Balance-training trainees on both the individual intake questionnaire and the group-based program.

\section{Materials and Methods}

The study adhered to the principles of the Declaration of Helsinki. The study did not fall under the Medical Research Involving Human Subjects Act (non-WMO research); therefore, an official approval of this study by the ethical committee was not required in the Netherlands[13]. The informed consent materials explained that by voluntarily returning the survey and responding to the interview questions, the trainees had agreed to participate in the research Anonymity of the respondents had been guaranteed, and withdrawal from the study or participation in the Balance-training had been allowed at any point in the timeline.

\section{Study intervention}

Balance-training was developed as a 10 -week programme, in five group-based sessions every other week, including daily homework. The training is built on three pillars: i.e., psycho-education, peer support, and mindfulness-based stress reduction (MBSR) exercises. All background information and exercises have been described in a manual, which the trainees received together with a CD that supports homework exercises in the beginning of the Balance-training. The total program has been developed through an iterative process by a healthcare coach trained in MBSR and with clinical expertise in ICU work and follow-up clinics (HO), guided by former ICU patients and their relatives. The attained knowledge and experiences have been included in the design and content of the Balance-training, as they are valuable inside information aimed at the targeted population.

Psycho-education has been used to provide information on PICS, recognizing symptoms, and acknowledgement of personal accomplishments. This was hypothesized to increase self-efficacy and self-management in the complex situation after an ICU admission [14]. Additionally, reducing stress levels, balancing energy, communication, and individualized informational needs have been addressed. Between the sessions, the coach supported the trainees by mail or telephone as requested. Peer support has been included to stimulate storytelling and the sharing of experiences about recovering from a critical illness [12]. This form of peer support induced acceptance of one's own situation and increased the ability to adapt in the face of social, physical and emotional challenges of life post ICU. In the fourth session, a former ICU-patient was scheduled to share her experiences and discuss these with the trainees. MBSR is based on centuries-old meditation techniques, which were introduced and guided during the Balance-training. MBSR is thought to work predominantly by developing mindfulness qualities to support coping with emotional and physical symptoms [15],thus focusing on the awareness of what is currently being experienced in the body and mind. This allows emotions, physical sensations, and thoughts to be noticed without judging. Acceptance of the experience in the present moment of the circumstances stimulates choosing from a fresh, current freedom, and the abilityto deal with stressful situations, pain or fatigue [15]. Additionally, MBSR may decrease anxiety, depression, frustration, and traumatic stress through a more fundamentally friendly self-attitude $[16,17]$. It has been proven effective in many patient groups for managing stressful situations, e.g., breast cancer survivors [18] and patients with multiple sclerosis [19]. Moreover, mindfulness training, delivered by telephone, was suggested to be a feasible and acceptable strategy for reducing psychological distress among ICU survivors in thetwo months post discharge [20].

Any adult former ICU patient familiar with the Dutch language could become a trainee in the Balance-training. The training was independent of hospital-based interventions or health centers and therefore not free of charge for the trainees. Some level of physical, cognitive, and emotional recovery, based on self-assessment, was desirable and was discussed with the trainer on beforehand to get started with the Balance-training. The amount of effort needed to profit from the training was also emphasized. In case of personal interest, or being urged by a GP or other healthcare provider, the former ICU patients started with an intake assessment to evaluate their current level of well-being. The Balance-training was striving for self-awareness, recognition, adaptation and self-management, with personal growth as the ultimate goal.

\section{Study design}

The design of this pilot study was longitudinal and mixed method, with quantitative and qualitative elements. Nurse students from the University of Applied Sciences (HAN) acted as independent researchers, guided by their supervisor (LV). To begin, an explorative literature search on the theoretical background of the Balancetraining was performed. The search was conducted using the electronic databases PubMed, Cinahl, and Google scholar to identify available publications on symptoms of PICS and the effectiveness of MBSR. Searches included terms occurring anywhere in the title and main text, with publication in the last 10 years, and were limited to the English language. The following terms were used in the search builder: 1) "critical illness," and 2) "mindfulness," OR "self-help groups" OR "consumer health information," combined with one of the following keywords: "intensive care," "follow-up," or "after care." This search was completed by selecting additional publications from the reference sections of the included articles. Subsequently, a measurement instrument to monitor the progress on the individual goals and effects of the Balance-training has been composed, framed by this literature search. This newly composed measurement instrument was mailed to the respondents before $(=t 1)$, immediately at the end $(=t 2)$, and three months after finishing $(=\mathrm{t} 3)$ the Balance-training. Finally, the experiences of the trainees with the Balance-training have been further explored by semi-structured face-to-face interviews, lasting approximately 30 minutes. These were completed to learn from the experiences of the trainees, as pertaining to the period between two and eight weeks after Balance-training.

\section{Study population}

Ten former ICU patients in a central region of the Netherlands started their Balance-training in January or March 2016, with the same coaches and outline of the course. All trainees were eligible 
Citation: van Mol M, Oonk H, Vloet L (2017) Lessons Learned: 'Balance-training' as a New Method Supporting former Intensive Care Patients in Adaptation and Self-management. Int J Psychol Behav Anal 2: 134. doi: https://doi.org/10.15344/2017/2455-3867/134

Page 3 of 6

for the study, of which eight agreed to participate. Two trainees refused to participate because they found the training intensive and confronting to their limitations. They would rather spend all their energy in reaching their own rehabilitation goals. No one dropped out of the study. Table 1 describes study participants characteristics. The ICU experience had been at least nine months earlier, and sufficient physical recovery, some level of reflection, and emotional balancing of the participants was expected.

\section{Measures and data analyses}

The results of the literature search were analyzed with the GRADE approach to assess the quality of the publications [21]. The demographic variables 'Sex', 'Age', 'Ethnic background, 'Health indication', 'Psychological health', and 'Education' were measured and have been reported as percentages. The variables 'Personal wellbeing', 'Self efficacy', 'Self-management', 'Depression', 'Anxiety', and 'Stress' were measured at $\mathrm{t} 1, \mathrm{t} 2$ and $\mathrm{t} 3$ and have been reported as individual scale scores. Further analysis of the quantitative results has not been performed due to the limited number of respondents.

The semi-structured interviews with open-ended questions were used to explore the participants' perceptions of the Balance-training. To analyze the data, common methods have been followed[22]. All interviews were audiotaped, transcribed for verbatim analysis, and returned for validation to the participants. Coding and categorizing were checked and compared between the nurse-students after the first interview to learn and raise similarity between observational judgements. In the case of disagreement, their supervisor (LV) was consulted. Identifying themes were applied manually to analyze the qualitative results until no new information emerged [23]. Transcripts were studied for content line-by-line, and codes were noted in an Excel database, which created a label for each sentence. Cross-checking of the emerging labels was established with the supervisor. The project group compared common pattern to identify similarities and differences of the participants' experiences. Then, these labels were grouped and categorized using broader themes. Thereafter, the final remaining themes were discussed and presented to key informants $(n=2)$ to reach a consensus.

\section{Results}

\section{Explorative literature review}

The literature search resulted in 17,689 publications, of which 41 were analyzed to identify factors related to the theoretical basis of the Balance-training. It was found that this course is the first intervention in ICU aftercare, which combined the positive effects of psychoeducation, MBSR and peer support.

The search also revealed that there was no existing valid, reliable, and feasible questionnaire for intake and evaluation of the Balancetraining. Therefore, applicable items from four measurement instruments were selected to provide an indication of the effectiveness of the intervention on the trainees. The World Health Organization Quality of Life short version was used to assess personal well-being (e.g., physical health, psychological health, and social relationships) [24]. The 26 statements provided response categories from 1 (most negative, e.g., very dissatisfied, very bad) to 5 (most positive, e.g., very satisfied, very well). The Dutch General Self-Efficacy Scale with 10 items concluded with the ability to react on difficult situations and setbacks [25]. Item responses ranged from 1 (totally wrong) to 4

\begin{tabular}{|c|c|}
\hline Demographic variable & $\mathrm{N}(\%)$ \\
\hline \multicolumn{2}{|l|}{ Sex } \\
\hline Men & $3(37.5)$ \\
\hline Woman & $5(62.5)$ \\
\hline \multicolumn{2}{|l|}{ Age category (in years) } \\
\hline $25-34$ & $1(12.5)$ \\
\hline $35-44$ & $1(12.5)$ \\
\hline $45-54$ & $2(25.0)$ \\
\hline $55-64$ & $3(37.5)$ \\
\hline $65-74$ & $1(12.5)$ \\
\hline \multicolumn{2}{|l|}{ Ethnic background } \\
\hline Dutch & $8(100.0)$ \\
\hline Other & 0 \\
\hline \multicolumn{2}{|l|}{ Health indication } \\
\hline Badly & $1(12.5)$ \\
\hline Quit well & $6(75)$ \\
\hline Well & $1(12.5)$ \\
\hline \multicolumn{2}{|l|}{ Psychological health } \\
\hline Badly & $1(12.5)$ \\
\hline Quit well & $4(50.0)$ \\
\hline Well & $3(37.5)$ \\
\hline \multicolumn{2}{|l|}{ Education } \\
\hline Non/primary school & 0 \\
\hline GCSE & $2(25.0)$ \\
\hline A-level & $3(37.5)$ \\
\hline College & $3(37.5)$ \\
\hline Other & 0 \\
\hline
\end{tabular}

Table 1: Demographic characteristics of the study participants.

(completely correct). The Patient Activation Measure comprised 13 items on self-management [26] with assessments between 1 (totally do not agree) and 4 (totally agree). The Depression Anxiety Stress Scale with 21 items evaluated the three domains of depression, anxiety, and stress [27]. Each domain contained summed items with responses ranging from 0 (not applicable) to 3 (always applicable). All items were in the Dutch language.

\section{Quantitative results}

Most of the respondents evaluated this newly composed questionnaire as suitable for the Balance-training. One respondent needed much focusing and time to answer the questions, while others found it easy to finish in a range of 10 to 30 minutes. The questionnaire triggered unwelcome memories of the ICU in one respondent.

The majority of respondents showed an individual improvement in their situation, as measured at $\mathrm{t} 3$. For example, self-management increased in five respondents and personal well-being was measured the same or increased in six respondents. Positive effects at $\mathrm{t} 3$ were also shown on self-management; depression; anxiety; stress level; knowledge, skills and confidence in managing their own health situation; physical functioning; and psychological wellbeing. The differences in $\mathrm{t} 1, \mathrm{t} 2$, and $\mathrm{t} 3$ as well as the effect size of the Balancetraining were not analyzed due to the limited number of respondents. 
Citation: van Mol M, Oonk H, Vloet L (2017) Lessons Learned: 'Balance-training' as a New Method Supporting former Intensive Care Patients in Adaptation and Self-management. Int J Psychol Behav Anal 2: 134. doi: https://doi.org/10.15344/2017/2455-3867/134

Page 4 of 6

\section{Qualitative results}

The emerging themes mentioned in the semi-structured interviews with the participants included increased of self-confidence, positive change in thoughts, convenient relaxation, knowing one's own boundaries, comfortable sleep, attention to myself and others, more insights in myself and the new situation, and comprehension of consequences. However, the most recalled and highly valued was peer support for sharing stories and experiences. Table 2 summarizes the qualitative results; the verbatim quotes serve as examples of their associated themes and were selected based on their clarity and illustrative appropriateness. All respondents stated that they appreciated the Balance-training and would recommend it to others. Participants assessed the day, duration, and location of the course as positive, with all relevant topics included in the outline. An ideal composition of six to eight participants per course contributed to an excellent atmosphere, which offered the possibility to learn and grow from their own and others' experiences.

Most effective were the MBSR exercises, which established awareness of a person's emotional state and helped to regenerate in life.

"But I could no longer express my feelings because I felt in a scallop. People say to be happy because of living, what are you nagging. But I couldn't cope with it, didn't tell anything to anybody. I started to think getting crazy." (ID\#1)

"Energy is a problem, especially after my critical illness. So, how can I handle this and stay in a balance. I learned a little bit better to accept the consequences." (ID\#3)

"I feel emotionally drained." (ID\#7)

"Well, I've had so many troubles, I became really angry about it. Nobody gave an explanation, I had to deal with that all. I learned to live in the 'now', in what is currently the situation. That's a good point." (ID\#1)

\section{Discussion}

This pilot study to explore the experiences of trainees on both the intake questionnaire and the Balance-training program revealed two strong points. First, the added value of psycho-educational groups supported self-awareness, recognition, adaptation and selfmanagement in ICU survivors. A major advantage of this face-toface contact might relate to showing group members how to interact, thus reducing isolation, and how to help each other [14]. Creating and guiding opportunities to practice new personal learning have been accomplished in the group-based Balance-training. Although not measured in the current study, this directed learning seemed stimulated through interaction between the trainees. Informal peer support might enlarge opportunities for emotional expression in a safe place, thereby fostering the development of hope and solidarity. In contrast to other MBSR interventions, such as the telephone-based mindfulness training [20], the combination of the three pillars in the Balance-training could provide a complete package in striving for personal growth in ICU survivors. Positive effects on the goals of the training were found, i.e., skills and confidence in managing their own health situation, depression, anxiety, stress level, knowledge of physical functioning, psychological wellbeing and social relations. Moreover, it seemed that this new intervention was feasible, acceptable and potentially effective.

\begin{tabular}{|c|c|}
\hline Main theme & Units of meaning \\
\hline Increase inself-confidence & $\begin{array}{l}\text { "I have confidence now that I can judge } \\
\text { going to my GP or solve the health } \\
\text { problem myself." }\end{array}$ \\
\hline $\begin{array}{l}\text { Positive change } \\
\text { inthoughts }\end{array}$ & $\begin{array}{l}\text { "The Balance-training supported me } \\
\text { in a change of thoughts, I have made a } \\
\text { beginning during the training and went } \\
\text { straight ahead." }\end{array}$ \\
\hline \multirow[t]{2}{*}{ Convenient relaxation } & $\begin{array}{l}\text { "The training provided awareness on } \\
\text { calming down in the surroundings. They } \\
\text { call it meditation, and I'm practicing } \\
\text { regularly now." }\end{array}$ \\
\hline & "Meditation helps in slowing down." \\
\hline \multirow[t]{2}{*}{ Knowing own boundaries } & $\begin{array}{l}\text { "In relation to my boundaries, I still go } \\
\text { over it now and then, but I look at it } \\
\text { differently now. And sometimes I can } \\
\text { even say that it is enough for today." }\end{array}$ \\
\hline & $\begin{array}{l}\text { "Mindful in the meaning of a friendly } \\
\text { attitude towards myself, without } \\
\text { judgment. And for me personally also to } \\
\text { respect my boundaries, I used to be too } \\
\text { tight for myself." }\end{array}$ \\
\hline \multirow[t]{2}{*}{ Comfortable sleep } & "The body scan is helping to get asleep." \\
\hline & $\begin{array}{l}\text { "I didn't feel refreshed in the morning } \\
\text { because of busy activities while sleeping, } \\
\text { the body scan helped to feel more rest so } \\
\text { that I stay in my bed whole night." }\end{array}$ \\
\hline \multirow[t]{2}{*}{$\begin{array}{l}\text { Attention to myself and } \\
\text { others }\end{array}$} & $\begin{array}{l}\text { "What I encountered, for example social } \\
\text { life and work, is how to react to different } \\
\text { experiences from family and myself." }\end{array}$ \\
\hline & $\begin{array}{l}\text { "It opened my eyes, I have become a little } \\
\text { softer. I take care for other people and } \\
\text { myself more than before the training." }\end{array}$ \\
\hline \multirow[t]{2}{*}{$\begin{array}{l}\text { Insights in myself and } \\
\text { new situation }\end{array}$} & $\begin{array}{l}\text { "But that wasn't the case, I recognized that } \\
\text { it had to do with the period I was in the } \\
\text { ICU. Staying in that bed for so long. I have } \\
\text { noticed this for the first time during the } \\
\text { Balance-training." }\end{array}$ \\
\hline & $\begin{array}{l}\text { "Then you realize, we are with family } \\
\text { together now but it could have been } \\
\text { totally different. That is emotional, } \\
\text { although those moments have become } \\
\text { less frequent. The valuation of other } \\
\text { people has become more positive." }\end{array}$ \\
\hline $\begin{array}{l}\text { Comprehension of } \\
\text { consequences }\end{array}$ & $\begin{array}{l}\text { "Energy is a problem, especially after my } \\
\text { critical illness. So, how can I handle this } \\
\text { and stay in a balance. I learned a little bit } \\
\text { better to accept the consequences." }\end{array}$ \\
\hline
\end{tabular}

Table 2: Summary of the qualitative results.

Second, the current World Health Organization definition of health has been proposed for reformulation in a more positive direction. This new idea is positively expressed as "Health as the ability to adapt and to self-manage in the face of social, physical and emotional challenges" [8]. Balance-training has connected strongly to this idea through supporting self-management and the adaptation of ICU survivors to their new situation. Additionally, the context of positive psychology provided a well-founded theoretical framework for applications to increase individual well-being; both enhancing competencies that promote positive emotions and managing emotionally stressful situations contributed to personal growth [28]. Derived from this concept of positive psychology, the balance-training proved to be a 
Citation: van Mol M, Oonk H, Vloet L (2017) Lessons Learned: 'Balance-training' as a New Method Supporting former Intensive Care Patients in Adaptation and Self-management. Int J Psychol Behav Anal 2: 134. doi: https://doi.org/10.15344/2017/2455-3867/134

Page 5 of 6

successful personalized method applicable in the daily life of ICU survivors.

Mindfulness training has been used in many clinical interventions [15]. It is a contained idea that includes many forms and applications. In Balance-training, the coach has adapted the classical 8-week MBSR training into a shortened version because of the ability of the trainees to take on a new load. Other studies suggested that even short programs in mindfulness meditation could produce positive results on brain and immune function [29]. Further research on long-term effectiveness is needed to underscore the Balance-training method.

It has been suggested previously that patients' admittance to post-ICU interventions should be improved in general [30]. Some promising hospital-based interventions have been developed to serve the heterogeneous population of ICU survivors. However, problems regarding who should be included, how to reduce drop-out, and how to make these interventions cost-effective have not been solved until now. Balance-training might provide some valuable clues. The trainees were proactive and signed themselves up for the whole program, thus, reducing drop-out to a minimum. This was a fundamental choice, in reference to self-management and awareness, as the first step in their process of acceptance and adaptation. Although the nine months after the ICU period was arbitrary, it leveled out the most unstable survivors. The added value of the coach's ICU background and MBSR trainer was of utmost importance in the development of the Balancetraining because of the special needs and possibilities for the support of ICU survivors. In particular, this provided an individualized training for each trainee, equalizing each participant's input, and creating a safe atmosphere to share experiences. A disadvantage of the Balance-training is the financial costs for the trainee; therefore, incorporating the new method in health insurance packages has been advocated.

The qualitative analysis in our study has been performed as stated in the methods paragraph. Although we do agree that more profound methods to fundamentally analyze interviews with respondents could have been performed, for example the new interview methodology for studying people's beliefs based on Ajzen's Theory of Planned Behavior [31], that outcome was not the purpose of the study. We aimed to do a first exploration of the experiences of trainees in the Balancetraining on both the individual intake questionnaire and the groupbased program. The labeling and categorizing, with reporting of some example quotes, have accordingly been done to get an idea about the opinions and experiences of the trainees. There are a wide variety of methods that are common in qualitative research [32] which tends to assume that each researcher brings a unique perspective to the study. Confirmability refers to the degree to which the results could be confirmed or corroborated by others. There are a number of strategies for enhancing confirmability; therefore, we executed the procedures for checking and rechecking the data throughout the study period. The analysis has been done inductively and logically, describing the patterns and plausible explanations through inductive analysis, thereafter searching for competing themes and explanations [32]. It is a matter of considering the weight of evidence and looking for the best fit between data and analysis. The participants were in a vulnerable situation when they were interviewed. Therefore, some deepening questions were not asked, in respect to the emotional state and reluctance to relive some parts of the ICU-period or the Balancetraining [22]. The results are representative for the participants experiences but cannot be generalized. The findings may be applicable to similar contexts.
The value of our study has predominantly been the overall positive judgment of the new method of Balance-training, which combines psycho-education, methods to increase self-management, reduce stress and balance energy and peer support. This indicated that further development of the method is justifiable. Furthermore, the method addresses the needs of former ICU patients and strengthens them to bring up their symptoms in the somewhat untouched field of long-term ICU follow-up.

\section{Limitations}

There are certain limitations that need to be acknowledged in the present study. First, the study was performed for a relatively small number of respondents. Therefore, the external validity of the study is open to question. Due to statistical limitations, an interpretation of the causality in the relationships between variables is not possible. The causal effect of the Balance-training on wellness, self-efficacy, self-management, and anxiety remains to be explored. The natural course of rehabilitation should also be considered in the light of the positive effects too. Therefore, longitudinal studies including waitinglist control groups are needed to understand the causal and reciprocal relationships between the constructs and to validate the results of the Balance-training over time. Second, the data were obtained exclusively by self-reported questionnaires, potentially leading to socially desirable answers. In particular, the respondents valued their coach among other issues, which might bias the results through cognitive disassociation. The extensive questionnaire, including 70 items at three different time points, could evoke respondent fatigue. A short version of the measuring instrument is desirable. Finally, an international multicenter study is necessary to confirm or disprove the presented results.

\section{Conclusion}

Balance-training is a new method in the aftercare of ICU survivors and includes psycho-education, mindfulness-based stress reduction exercises, and peer support. This approach showed preliminary positive results in self-management and offered support and tools for taking care of one's own emotional and physical balance in life.

\section{Acknowledgement}

We would like to thank the former ICU patients and their relatives for sharing their stories with the investigators. We also appreciate the contribution of Manon Hofman, Nicolette Mak, Britt van der Meer, Evi Swinkels, Anouk Aleven, and Rowie Visser in data gathering. Their development process as nurse students stimulated for further analysis and reporting on the Balance-Training. Finally, the Balancetraining could not have been executed in the current form without the valuable help of Idelette Nutma, who balanced her life in recovery from a critical illness herself.

\section{Author's Contribution}

Substantial contributions to conception and design (HO, LV), acquisition of data (LV), or analysis and interpretation of data $(\mathrm{MvM}$, $\mathrm{HO}, \mathrm{LV}$ ),

Drafting the article $(\mathrm{MvM})$ or revising it critically for important intellectual content (HO, LV),

Final approval of the study (MvM, HO, LV).

\section{Competing Interests}

The authors declare that they have no competing interests. 
Citation: van Mol M, Oonk H, Vloet L (2017) Lessons Learned: 'Balance-training' as a New Method Supporting former Intensive Care Patients in Adaptation and Self-management. Int J Psychol Behav Anal 2: 134. doi: https://doi.org/10.15344/2017/2455-3867/134

Page 6 of 6

\section{References}

1. Davidson JE, Harvey MA (2016) Patient and Family Post-Intensive Care Syndrome. AACN Advanc Crit Care 27:184-186.

2. Elliott D, Davidson JE, Harvey MA, Bemis-Dougherty A, Hopkins RO, et al, (2014) Exploring the Scope of Post-Intensive Care Syndrome Therapy and Care: Engagement of Non-Critical Care Providers and Survivors in a Second Stakeholders Meeting. Crit Care Med 42: 2518-2526.

3. Parker AM, Sricharoenchai T, Raparla S, Schneck KW, Bienvenu OJ Needham DM (2015) Posttraumatic stress disorder in critical illness survivors: a metaanalysis. Crit Care Med 43: 1121-1129.

4. Harvey MA, Davidson JE (2016) Postintensive Care Syndrome: Right Care, Right Now... and Later. Crit Care Med 44:381-385.

5. Hill A, Fowler R, Pinto R, Herridge M, Cuthbertson B, Scales D (2016) Long-term outcomes and healthcare utilization following critical illness-a population-based study. Crit Care 20: 1.

6. Pandharipande PP, Girard TD, Jackson JC, Morandi A, Thompson JL, et al (2013) Long-term cognitive impairment after critical illness. N Engl J Med 369: 1306-1316.

7. Needham DM, Davidson J, Cohen H, Hopkins RO, Weinert C, et al. (2012) Improving long-term outcomes after discharge from intensive care unit: Report from a stakeholders' conference. Crit Care Med 40: 502-509.

8. Huber M, Knottnerus JA, Green L, van der Horst H, Jadad AR, et al. (2011) How should we define health? BMJ 343: d4163.

9. Griffiths J, Barber V, Cuthbertson B, Young J (2006) A national survey of intensive care follow-up clinics. Anaesthesia 61: 950-955.

10. Major M, Kwakman R, Kho M, Connolly B, McWilliams D, et al. (2016) Surviving critical illness: what is next? An expert consensus statement on physical rehabilitation after hospital discharge. Crit Care 20: 354.

11. Sottile PD, Moss M (2016) The Importance of Coping in Critically III Patients. Crit Care Med 44:1797-1798.

12. ICUsteps, The intensive care patient support.

13. CCMO Central Committee on Research Involving Human Subjects (CCMO).

14. Cowls J, Hale S (2005) It's the activity that counts: What clients value in psycho-educational groups. Can J Occup Therapy 72:176-182.

15. Baer RA (2003) Mindfulness training as a clinical intervention: A conceptual and empirical review. Clin Psychol Sci Pract 10:125-143.

16. Van der Kolk B (2014) The body keeps the score. New York: Viking books $443 \mathrm{p}$.

17. Miller JJ, Fletcher K, Kabat-Zinn J (1995) Three-year follow-up and clinical implications of a mindfulness meditation-based stress reduction intervention in the treatment of anxiety disorders. Gen Hosp Psychiatry 17: 192-200.

18. Boyle CC, Stanton AL, Ganz PA, Crespi CM, Bower JE (2017) Improvements in emotion regulation following mindfulness meditation: Effects on depressive symptoms and perceived stress in younger breast cancer survivors. J Consult Clin Psychol 85: 397.

19. Blankespoor RJ, Schellekens MP, Vos SH, Speckens AE, de Jong BA (2017) The Effectiveness of Mindfulness-Based Stress Reduction on Psychological Distress and Cognitive Functioning in Patients with Multiple Sclerosis: a Pilot Study. Mindfulness 1251-12588.

20. Cox CE, Porter LS, Buck PJ, Hoffa M, Jones D, et al. (2014) Development and preliminary evaluation of a telephone-based mindfulness training intervention for survivors of critical illness. Annals Am Thorac Soc 11:173181.

21. Higgins JP, Green S (2011) Cochrane handbook for systematic reviews of interventions. Vol. 4: New Jersey: John Wiley \& Sons Ltd 672 p.

22. Olsen KD, Nester M, Hansen BS (2017) Evaluating the past to improve the future-A qualitative study of ICU patients' experiences. Intensive Crit Care Nurs 43: 61-67.

23. Mason M (2010) Sample Size and Saturation in PhD Studies Using Qualitative Interviews. Forum Qual Soc Res 11: 8.
24. Whoqol Group (1998) Development of the World Health Organization WHOQOL-BREF quality of life assessment. Psychol Med 28: 551-558.

25. Schwarzer R, Jerusalem M (2010) The general self-efficacy scale (GSE). Anxiety, Stress, and Coping 12: 329-345.

26. Hibbard JH, Stockard J, Mahoney ER, Tusler M (2004) Development of the Patient Activation Measure (PAM): conceptualizing and measuring activation in patients and consumers. Health Serv Res 39: 1005-1026.

27. Antony MM, Bieling PJ, Cox BJ, Enns MW, Swinson RP (1998) Psychometric properties of the 42-item and 21-item versions of the Depression Anxiety Stress Scales in clinical groups and a community sample. Psychol Assess 10:176.

28. Snyder CR, Lopez SJ (2009) Oxford handbook of positive psychology. New York: Oxford University Press.

29. Davidson RJ, Kabat-Zinn J, Schumacher J, Rosenkranz M, Muller D, et al. (2003) Alterations in brain and immune function produced by mindfulness meditation. Psychosomatic Med 65: 564-570.

30. Herridge M, Cox C (2012) Linking ICU practice to long-term outcome: fostering a longitudinal vision for ICU-acquired morbidity. Am Thoracic Soc186: 299-300.

31. La Barbera F, Riverso R, and F. Verneau F (2016) Understanding beliefs underpinning food waste in the framework of the theory of planned behaviour. Calitatea17: 130

32. Patton MQ (1999) Enhancing the quality and credibility of qualitative analysis. Health ServRes 34: 1189. 